\title{
Current barriers and possible solutions to effective project team formation and deployment within a large construction organisation
}

\section{ABSTRACT}

The characteristics of the construction industry present an extremely challenging context for effective human resource management (HRM). The dynamic projectbased nature of the industry results in extreme fluctuations in organisations' workloads and requires teams to form, develop and disband relatively quickly. Thus, the importance of efficient management of employee resourcing activities cannot be understated. This paper reports on the findings of research which explored employee resourcing practices within large UK construction firms. The results suggest that managers currently attempt to carry out some strategic planning with regards to employee resourcing, but that this does not necessarily translate into effective operational practice which simultaneously takes account of organisational, project and individual employee needs. A new approach for more effective employee resourcing decision-making, based on encouraging the involvement of the employees in the deployment process, is put forward as a management tool which informs effective team formation and deployment. However, this will require the acceptance of both decision-support technology and of employee input into what is currently a tacit, management-oriented decision process.

Keywords: construction industry, human resource management, teams, employee involvement, human resource information system (HRIS) 


\section{INTRODUCTION}

The construction sector represents one of the most dynamic and complex industrial environments. It is a large industry within the UK employing approximately 1.5 million people, comprised of mainly small firms [1]. It is also a project-based sector within which individual projects are usually custom-built to client specifications [2]. These projects constitute the construction organisation's workload. Thus, fluctuations in the economic markets are reflected in considerable variations in the number, size and type of projects undertaken by construction organisations over time. A key characteristic of the industry's output is that the finished product is largely nontransportable and must therefore be assembled at a point of use, usually outside $[1,2]$ and geographically dispersed.

These industry characteristics present a challenging context for effective management of human resources. Their impact is particularly apparent within the larger contractors, whose focus is on managing the construction process with a few directly employed managers leading teams of outsourced trades contractors [3]. Whilst the increasing use of subcontractors has allowed contractors to pass on risk and achieve greater flexibility, it has also made project co-ordination more complex, so more highly skilled and experienced management is required [1, 3]. Furthermore, the fluctuations in the organisations' workload cause significant variations in firms' staffing needs, both in terms of volume and professional skill profiles. The changing requirements of construction work also necessitate the formation of bespoke teams each time a new project is awarded. Planning for such deployment can be difficult given the short-term fluctuations in workloads and the geographical dispersal of the 
projects. This requires construction contractors to maintain a highly mobile and flexible workforce with significant professional and managerial capabilities, allied to effective employee resourcing practices. However, despite these challenges, few studies have considered the specific context and challenges dynamic and complex project-based industries present $[4,5]$ or have sought to capture effective approaches to employee resourcing within the construction sector [6]. The research in this paper begins to address this shortfall by examining how modern construction contractors in the UK manage the resourcing function and how these activities could be adapted and improved in order to improve project and organisational performance as well as employee job satisfaction. The paper begins with an examination of the employee resourcing function and discusses its centrality to the efficacy of the HRM function within construction organisations. This is followed by a discussion on the research methodology and findings, which are used to formulate a proposal for a new, more effective approach to managing the resourcing function within large construction firms.

\section{EMPLOYEE RESOURCING}

Employee resourcing is one of the key human resource management (HRM) functions within construction organisations. It focuses on matching human resources to the strategic and operational needs of the organisation and ensuring the full utilisation of those resources [7]. This is achieved by meeting the HRM objectives of staffing, performance and administration [8]. Table 1 summarises these HRM objectives, and categorises the related employee resourcing activities and the specific tasks involved which are explained in more detail below. 
Table 1. Employee resourcing activities

Staffing

\section{Human resource planning}

The primary concern of human resource planning (HRP) is to integrate the strategic and operational requirements of the business with a workforce equipped to provide the services and products that customers demand [9]. Some doubts exist as to whether HRP is a worthwhile activity given the turbulence of modern business environment [9]. However, Laufer et al [10] argue for the crucial importance of planning, especially within the dynamic project-based sectors, in that it can help reduce uncertainty, introduce structure and create order and action. Turner [11], in support of this view, distinguishes two fundamental components to effective HRP: establishing a strategic human resource forecast (SHRF) and preparing a human resource plan (HRP). The SHRF is a key input to the direction of an organisation. HRP is developed to act as a means to achieve strategic HRM targets, and thus forms the output [11].

\section{Recruitment and selection}

A reconciliation of the HRP outcomes with the shorter-term operational conditions of the business indicates the levels of recruitment required. Larraine and Cornelius [12] highlight the importance of:

- analysing the organisation’s long-term resource requirements; 
- clear advertising of the vacancies via appropriate media thereby ensuring the widest possible pool of suitable candidates is attracted and much desired choice in the selection process achieved;

- determining appropriate reward linking the process with other HRM strategies;

- the measurement, review and evaluation of the selected candidates' performance being fed into the organisation's performance management systems.

By emphasising the continuity of the process and the links with other HRM systems Larraine and Cornelius' approach reveals the vital importance of effective recruitment and selection process; ensuring an appropriate supply of skilled staff that can positively contribute toward the achievement of the business objectives. This is especially true within project-based sectors where the often short-term assignments can suffer detrimental consequences should staff shortage delay projects at any stage. It is arguably even more crucial for the construction industry as it is currently experiencing increasing difficulties in attracting skilled staff $[13,14]$.

\section{Team deployment}

The staffing function within project-based organisations is also concerned with team formation and building, and the deconstruction and redeployment of teams [15-17]. The fundamental requirement of effective team deployment is to select team members carefully on the basis of their personality and skills [18]. This is crucial; enforced changes in key project personnel are highly disruptive to project performance [19]. Many typologies and approaches to achieving effective team composition exist. For example, Belbin’s [20] team role model and Margerison and McCann’s [21] team management wheel can aid the selection of individuals who together form a balanced 
and complementary workgroup. However, effective team performance also relies on members' abilities to successfully integrate their individual actions [22]. In addition, Gray [5] found that organisational climate affects the success of a project team. Characteristics, such as freedom of expression, participation in the definition of goals and innovation were found to positively impact project outcomes. He concluded: “ $a$ low threat, secure and stable environment in which individual contribution is maximised within a distinctive team culture offers the optimum environment for successful project outcomes" [5]. This kind of climate rarely exists within turbulent project environments and so effective leadership is vital in defining team direction and in ensuring their optimum performance [22, 23].

\section{Exit}

The monitoring and management of exit from the organisation is best carried out on an on-going basis and its outcomes applied into the organisational learning processes as they emerge [24]. The management of involuntary forms of exit, such as redundancies, retirements or dismissals, should adhere to legal and procedural guidelines [24]. Absence, employee turnover and voluntary means of exit from the organisation may, on the other hand, be managed through performance and career management processes.

\section{Performance}

Performance and career management mechanisms focus on maximising individual, team and organisational performance whilst facilitating employees’ career development [25]. Performance management systems, particularly those aimed at 
evaluating team performance, via a composite of qualitative and quantitative measures, can also help assess the complex sum of variables that contribute to effective team/ project performance. Skilfully operated systems provide a useful tool for managing the balance between the competing organisational, project and individual employee priorities, needs and preferences.

\section{HR administration}

HR administration focuses on the collection, storage and use of employee data and supports the monitoring and analysis of HR information [26]. Contemporary human resource information system (HRIS) solutions provide sophisticated instruments to aid this process [27]. The most advanced web-enabled software interfaces with other administrative programmes and include "self-service” capabilities where individual employees update their own records which can subsequently be used in the strategic HRP activities. This makes process integration easier, reduces managers' administrative workload and encourages employee involvement among the numerous other benefits.

\section{Employee involvement}

Employee involvement (EI), or empowerment as the concept if often termed, is aimed at achieving staff commitment and participation through increasing employee voice and decision-making power $[8,25]$. In essence, it is about increasing organisational effectiveness through manager and employee collaboration and through sharing 
power and control [28]. It has been found a particularly effective way to managing change [25], improving performance [29], ensuring customer satisfaction and encouraging innovation [30]. Despite this, EI has received relatively little attention within the construction industry [31-33].

\section{RESEARCH METHODOLOGY}

An interpretative qualitative framework was adopted for the investigation of the current resourcing practices within large UK construction contractors. Much of the previous research on construction employee resourcing has focused on examining particular aspects of the function, such as recruitment and selection [34], project allocation [35, 36] or team building [15], adopting largely quantitative methodologies and developing solutions that primarily seek to satisfy the organisational/ project requirements and objectives. These approaches tend to be normative and have ignored the benefits that a tailored strategic approach and qualitative methodologies can offer. However, two challenges had to be overcome. Firstly, gaining an understanding of the complexities of the resourcing process and the approaches used to manage the function is problematic given the rapidly changing environment within which construction contractors operate [37]. Secondly, the researchers had no a priori knowledge of the likely approach adopted by construction companies from which a hypothesis could be derived. Therefore, an inductive methodology was chosen which allowed for the examination of the resourcing process from a variety of stakeholder perspectives with the aim of gaining a holistic view as to how the function is managed [37]. The methodology also made the collection of in-depth case study material 
possible [38], which allowed employee resourcing activities to be investigated from several perspectives for single project examples.

The data were collected via semi-structured interviews $(n=50)$ within a leading construction organisation based in the UK. The organisation was chosen as they operated throughout the country, their activities spanned every major sector of construction activity and because they were experiencing a phase of rapid expansion allied to increasing economic activity within the industry. They therefore represented a 'typical' example of a large, multi-disciplinary construction firm currently enjoying the buoyant construction market. They also saw addressing the problems inherent in the resourcing process as a key strategic priority. The participants comprised of senior HRM staff (4), directors (4), operational senior managers with responsibility for resourcing decision-making (7), and project-based employees at various levels of the organisation (35). A research instrument was developed to guide the discussions to cover all the major topics within employee resourcing and HRM these also incorporating issues specific to project-based sectors. The instrument was also designed to collect the participants' personal details, such as age, length of service in, educational background and personal/family status. The interviews were recorded, transcribed verbatim and then coded and analysed using $\mathrm{NVivo}^{\mathrm{TM}}$ qualitative analysis software. NVivo proved invaluable in aiding the codification and organisation of the research material and also in allowing for exploratory searches to be carried out on keywords, nodes and/ or attributes. Summary statement matrices and thematic networks were used to aid data reduction, and to highlight common themes as well as contradictions within the data [39]. 


\section{FINDINGS AND DISCUSSION}

The strengths and weaknesses of the current approach taken to employee resourcing by this company are explained below in relation to the essential components of employee resourcing function outlined in Table 1.

Human resource planning - integrating resourcing requirements with business objectives

HRP was managed at an organisation-wide level but with certain aspects being devolved to operational managers. An overall strategic plan was put forward at board level with targets for each division to achieve with regards to staff development and retention. Senior divisional managers then reconciled these against the resourcing requirements with a view of ensuring that appropriately qualified and skilled staff were available and that there was a constant supply of new staff into their division. In the short-term this involved the formulation of a business plan and associated strategies to meet its objectives. It also included running “what if” scenarios by notionally allocating staff to projects for which the division had bid in order to identify the possible gaps and how quickly they could be filled. More organised forecasting included numerical HRP on volumes of staff required for meeting the objectives of the business plan. HRM specialists were consulted as to the employee development that supported the divisions' succession planning.

The outcome of the typical approach to HRP was that organisation could foresee gaps in their resources and HR capabilities in advance of projects coming on stream. 
Although this is useful, it was managed as a relatively isolated process in which the division explored its own staffing requirements largely out of context of the remainder of the organisation. This may be caused by the devolution of responsibility for the management of employee resourcing activities to divisional directors and senior operational managers, a common tendency also found by Druker and White [3].

This type of strategic HRP suggests a strong likelihood of the organisation effectively integrating resourcing requirements with the business objectives. However, doubts existed as to whether HRP was a worthwhile activity given the turbulence and unpredictability of contemporary organisational life. In reality, this depends on how well HRP information is used in informing other areas of employee resourcing decision-making. A clear example is the direct link between SHRF and recruitment and selection processes.

Recruitment and selection - core interpersonal qualities crucial to maintaining organisational culture

A recent rapid growth in the organisational workload had demanded a sharp increase in the recruitment of new staff at all levels. This had included bringing in key senior personnel to run major projects, whole project teams and a number of support staff, such as HRM personnel, IT and administrative support. Despite extensive recruitment efforts, only around 50\% of the staff recruited had been taken on as permanent employees, with the remaining shortfall being made up with temporary agency staff. Additional pressures on the recruitment and selection process had also become apparent from the need to shift towards new market opportunities in the PFI and 
commercial building sectors following a parallel decline in infrastructure works over the past few years. Different management competencies were required for such positions, which were difficult to acquire.

Word-of-mouth recruitment and headhunting played a significant role in identifying new managers. This was to ensure that new entrants has core interpersonal qualities such as a keenness to work as part of a team, assertiveness (but not aggression), the ability to fit in within the organisational culture and good communication skills. Technical competence, previous experience, personal skills and knowledge and personal ambition were also seen as important characteristics of the managers that were likely to take the business forward. One innovative approach was that senior managers and personnel staff sought to determine these qualities through the provision of scenarios, a selection interviewing technique known as behavioural interviewing. Divisional managing directors monitored the process for senior positions, but lower level vacancies were filled at the discretion of line managers at a project level. This decision-making protocol proved to be effective.

Senior managers and employees alike discussed the importance of recruitment and selection decisions if the culture, which had ensured the retention of many of the organisations' longest standing staff, was to be maintained. The influx of so many new staff had had a marked negative effect in that it has contributed to a dilution of the strong culture upon which the organisation had been founded. 
Graduate recruitment - holding back the improvement of the industry's resources

Graduate recruitment and development currently holds back the expansion and improvement of the industry's resources as a whole. The entire process of recruiting and retaining quality candidates was identified as increasingly problematic. Fast track progression opportunities were offered to attract and retain suitable candidates with mixed results. On one hand it allowed for fresh ideas to be brought into management decision-making, but at the same time it had also resulted in resentment from some existing staff members and to certain individuals suffering from stress related problems.

Team deployment - short-term operational requirements over strategic objectives and employee preferences

Unsurprisingly, team formation and deployment was considered to be the most important of all the aspects considered under resourcing. However, the process was also considered extremely problematic to manage effectively due to the short-term time scales that apply to most construction projects. The need to select, form and deploy a team rapidly placed considerable strains on the efficacy of the processes currently in place. Staffing a project with entirely new personnel was considered too risky, which had resulted in people with known abilities being taken from existing projects, even where this could cause problems elsewhere. However, the dynamic nature of the staffing situation had inevitably led to a breakdown in this principle as needs overtook strategic objectives. Some major projects had ended up being staffed by teams of entirely new staff with little knowledge of the organisation or even by 
members external to the organisation. Selecting staff suitable for working with particular clients was therefore rendered extremely problematic and often led to teams having to be reformed during a project when they failed to perform as required.

The selection criteria for finding the suitable key people to head a project were almost unanimously stated being based upon:

1) availability,

2) previous experience (ability),

3) client preferences,

4) an individual's need for a particular job to gain experience or training,

5) individuals’ personal aspirations (including their career management/ development needs), and

6) the ability to devolve responsibilities (e.g. to develop and give experience to trainees on a project).

These priorities demonstrate the industry’s tendency to focus on meeting immediate organisational/ project needs, therefore placing employees’ preferences and aspirations well down the priority list. Staff appraisal records were rarely considered in the decision-making process, with subjective senior management decisions being relied upon in the majority of deployment decisions. This relied upon senior managers' abilities to fully understand the capabilities of their staff, a task that was increasingly difficult given the rapid intake (and turnover) of staff in the current competitive labour market. This intuitive process forms yet again an example of isolated systems. 
In addition to selecting the key personnel to head a project, ensuring a balance between the team members' strengths and weaknesses and their willingness to work together for a common aim was considered crucial. However, weaker team members who did not necessarily complement other managers were still placed into teams once they had been released from their previous roles, regardless of their requirements of the project deployment process. Again, the need to resource project teams rapidly and a lack of information to inform the process had led to a strong likelihood that inappropriate decisions would be made. Indeed, such practices appear to render the practicality of the principles of structured forms of team formation suggested by Belbin [20] and others highly questionable.

Team building - challenge of harmonising project level sub-cultures

Team building was also considered important to the success of a project. Various levels and forms of exercises were found to be in use. Larger more complex projects involving vast numbers of new staff included cultural integration exercises to provide focus and feeling of belonging, whereas smaller teams relied on informal social events to foster team synergy. Inevitably, long-term larger projects tended to develop their own team sub-cultures, partially as a result of the considered effort to integrate people within them to work better together. This had led to problems when it came to breaking up such teams as managers found it difficult to readjust into new team subcultures. 
Somewhat surprisingly considering the recognised importance of the team formation and team building in contributing to the overall success of the organisation, team effectiveness was not measured in any structured way. It was only considered where, for example, a team did not work well together. In such a case, making everybody aware of what is required of them and explaining why particular decisions were made was found an effective route to problem solving. If this was unsuccessful some of the project staff tended to be redeployed. This effectively defeated the original team selection process and hindered learning and knowledge sharing.

Exit - friendly organisational culture, individualised reward and training opportunities as retention factors

Salary and reward were mentioned as the main reasons for people leaving construction organisations. As a result, more individualised reward mechanisms, including a bonus system, had been initiated to prevent further problems from arising. A substantial investment in training, together with the maintenance of an informal and friendly organisational culture, was considered the organisation's strongest retention factor and were considered priorities for the organisation.

Career and performance management - challenge of rapid promotions and raised expectations, performance management system a missed opportunity

The recent organisational growth had resulted in many staff being promoted rapidly if they demonstrated appropriate leadership abilities. This has provided ambitious 
individuals the opportunity to further their careers at a fast pace and realise their aspirations far more quickly than would have been possible during a stable or downturn period. However, concerns abound as to the viability of such a practice in the future as the organisation will not be able to fulfil the employees’ raised aspirations and expectations in the future which was likely to have detrimental effect on staff turnover.

The high level of expectation on both new and existing managers had resulted in certain individuals suffering from stress related problems, as already alluded to in relation to graduate development. Consequently, these individuals were said to require extensive periods of time off work and careful reintegration once they returned. Thus, senior managers were faced with the negative consequences of stress related illnesses and the associated costs of time taken off sick, reduced productivity and morale, possible loss of valuable members of staff and the subsequent costs of recruitment and training of replacement personnel [40]. This appeared to be a symptom of the shortterm outlook toward the resourcing process.

The performance appraisal system formed the only formal means of providing a structure for promoting people. The annual appraisal interview provided an opportunity for discussing potential progression solutions and aided assessing individuals’ current job performance, developing personal development plans (PDPs) and recording employees' aspirations and preferences. However, the data gathered appeared to have little influence over recourcing decision-making processes. The fact that only paper copies of the appraisal records exist may have contributed to the limited use of the data as this may make it too difficult for managers to utilise it 
effectively. Furthermore, the appraisal linked to the graduate-training programme for junior staff, which also included a performance evaluation tool, was completely removed from the main performance management system. The resulting mass of paperwork, which such duplication promoted understandably, led to managers being reluctant to draw upon such information when making deployment decisions. A wellorganised and easily accessible IT-based system would allow for the data to be integrated in the resourcing processes.

HR administration - complexity of multiple systems and mechanisms

Much of the HR information was recorded and stored in manual paper files, with the remainder being stored within computerised systems which were operated in isolation of each other. For example, a bespoke database had been developed to hold employee records at a company wide level, training and development data was held on a separate system administered at a divisional level and payroll details were held on another system held by the personnel department. This resulted in several members of HRM and operational staff having to be involved in any HRM-related decision and the information being transferred across multiple systems [6]. It also made it very difficult to factor in other information such as appraisal data when making recourcing decisions. When discussing the possibilities of introducing an integrated employee self-service HRIS several contracts managers felt this would prove useful in reducing their administrative workload. Other suggested that it would be useful in promoting movement across divisions when demands on the business required it. 


\section{GREATER EMPLOYEE INVOLVEMENT - A WAY FORWARD?}

Given the dynamic project-based nature of the construction industry the importance of efficient management of human resource planning, recruitment and selection, team deployment, exit, performance management and HR administration cannot be understated. The findings of this exploratory study have clearly demonstrated the multiple and parallel challenges faced by managers in managing the process. For instance, the growing success of the organisation has resulted in severe staffing difficulties and the transformation of business direction has demanded broadly skilled and flexible employees to be developed. However, the long-term implications of reactive and informal recruitment and selection, team deployment and performance and career management have been largely ignored. This has led to sound strategic HRP intentions not being realised. This has potentially negative consequences in terms of the increased costs of employee welfare, poorer team performance and knowledge transfer and likely tensions for employees when attempting to manage work-life balance satisfactorily.

These findings suggest a need for there to be greater employee involvement (EI) in the resourcing process rather than it being maintained as a senior management activity, a suggestion supported by several previous research studies [8, 25, 28-33]. In essence, this would redress the imbalance of current employee resourcing decisions' focus on meeting the organisational/ project requirements, by incorporating the employees' needs and preferences into the process. This can be achieved via welldefined and transparent employee resourcing activities and procedures, supported by an integrated HRIS tool. The HRIS component should allow for effective collection, 
storage and use of employee data thereby ensuring the employees' needs and preferences can be easily incorporated into the decision-making. The system also has the potential to support effective delivery of HRP outcomes to operational recruitment and selection, team deployment and development activities and the inclusion of performance and career management data into the process. Thus, better-informed decisions can be made via transparent procedures with enhanced communications, which in turn facilitate greater employee morale and commitment.

On the basis of these recommendations, the company has recently invested in a HRIS package. At first the focus has been on serving the organisation's basic HR and training administration. Inclusion of employee self-service functionality and expanding the system capabilities beyond the basic administration are planned for the future. The on-going research project, to which the investigation into the current employee resourcing practices reported in this paper forms a part, will continue toward developing a generic strategic employee resourcing framework which will have broad applicability to address the problems of team formation and deployment across all project-based environments.

\section{CONCLUSIONS}

Team formation and deployment presents a vexing problem for many project-based environments, and none more so than construction where teams are created and disbanded rapidly in order to cope with bespoke project needs and fluctuating demand cycles. If the organisation forming the focus of this study is typical of other large firms operating within the industry, current approaches to managing this complex task 
appear to be reliant on fairly reactive and subjective decision-making processes by senior managers, who do not have access to the kind of information required to make fully informed and strategically aligned deployment judgements. Solving this problem appears to require both a cultural/attitudinal change in relation to incorporating employee opinions and needs into this process, as well as an effective decision-support mechanism in the form of readily available human resource information contained within an integrated database. This would redress the current imbalance of employee resourcing decisions via transparent management activities and procedures. The numerous benefits include effective delivery of strategic objectives to operational decision-making and consequently greater employee morale and commitment. However, whilst the advent of sophisticated web-enabled HRIS technology (coupled to employee self-service functionality) offers an opportunity to address the decision-support requirements, this will only be effective if the need to incorporate employees own needs and preferences is accepted. This presents a considerable challenge given the industry's historical reliance on line autonomy with regards to the deployment decision-making process.

\section{REFERENCES}

[1] Fellows R, Langford D, Newcombe R, Urry S. Construction management in practice, $2^{\text {nd }}$ ed. Oxford: Blackwell Science, 2002.

[2] Bresnen M. Organising construction: project and organisation matrix management, London: Routledge, 1990.

[3] Druker J, White G. Misunderstood and undervalued? Personnel management in construction. Human Resource Management Journal, 1995; 5(3): 77-91.

[4] Turner J, Müller R. On the nature of the project as a temporary organisation. International Journal of Project Management; 21(1): 1-8. 
[5] Gray R. Organisational climate and project success. International Journal of Project Management. 2001; 19(2): 103-109.

[6] Raiden A, Dainty A, Neale R. Employee resourcing for a medium-large UK contractor. In Uwakweh B, Minkarah I, editors. Proceedings of $10^{\text {th }}$ Triennial CIB Symposium on the Organisation and Management of Construction: Construction Innovation and Global Competitiveness, University of Cincinnati, Cincinnati, USA, 2002. p. $1429-1445$.

[7] Armstrong M, Baron A. Strategic HRM - the key to improved business performance, London: CIPD, 2002.

[8] Taylor S. People resourcing, $2^{\text {nd }}$ ed. London: CIPD, 2002.

[9] Marchington M, Wilkinson A. People management and development: human resource management at work, $2^{\text {nd }}$ ed. London: CIPD, 2002.

[10] Laufer A, Woodward H, Howell G. Managing the decision-making process during project planning. Journal of Management in Engineering, 1999; 15(2): 79-84.

[11] Turner P. Strategic human resource forecasting, London: CIPD, 2002.

[12] Larraine G, Cornelius N. Recruitment, selection and induction in a diverse and competitive environment. In Cornelius N, editor. Human resource Management, a Managerial Perspective, London: Thomson Learning, 2001.

[13] Pitzrick D. One company's approach to the recruitment and retention of engineers. Leadership in Management and Engineering, 2001; 1(1): 48-50.

[14] Shuster L. Meeting the staffing challenge. Civil Engineering - ASCE, 2000; 70(9): 70-71.

[15] Spatz D. Team building in construction. Practice Periodical on Structural Design and Construction, 2000; 5(3): 93-105.

[16] Mendelsohn R. Teamwork - the key to productivity. Journal of Management in Engineering, 1998; January/ February: 22-25.

[17] De Feis G. People: an invaluable resource. Journal of Management in Engineering, 1987; 3(2): 155-162.

[18] Katzenbach J, Smith D. The wisdom of teams: creating high-performance organisation, Boston: Harvard Business School Press, 1993.

[19] Chapman R. The likelihood and impact of changes of key project personnel on the design process. Construction Management and Economics, 1999; 17(1): 99-106.

[20] Belbin M. Management teams: why they succeed or fail, Oxford: ButterworthHeinemann, 1991. 
[21] Margerison C, McCann D. Team management: practical approaches, London: Mercury, 1991.

[22] Zaccaro S, Rittman A, Marks M. Team leadership. The Leadership Quarterly, 2001; 12(4): 451-483.

[23] Kliem R, Anderson H. Teambuilding styles and their impact on project management results. Project Management Journal, 1996; March.

[24] Huxtable J, Cheddie M. Strategic staffing plans. SHRM White Paper, 2002.

[25] Mabey C, Salaman G, Storey J. Human resource management, $2^{\text {nd }}$ ed. Oxford: Blackwell Business, 1998.

[26] Torrington D, Hall L, Haylor I, Myers J. Employee resourcing, London: IPM, 1991.

[27] CIPD. Software source at http://www.softwaresource.co.uk/, 2002.

[28] Honold L. A review of the literature on employee empowerment. Empowerment in Organisations, 1997; 5(4): 202-212.

[29] Cruise O’Brien R. Employee involvement in performance improvement: a consideration of tacit knowledge, commitment and trust. Employee Relations, 1995; 17(3): 110-120.

[30] Wickisier E. The paradox of empowerment - a case study. Empowerment in Organisations, 1997; 5(4): 213-219.

[31] Dainty A, Bryman A, Price A. Empowerment within the UK construction sector. Leadership and Organisational Development Journal, 2002; 23(6): 333-342.

[32] Jawahar Nesan L, Holt G. Assessment of organisational involvement in implementing empowerment. Integrated Manufacturing Systems, 2002; 13(4): 201211.

[33] Maloney W, Federle M. Employee involvement in engineering and construction. Journal of Management in Engineering, 1993; 9(2): 174-190.

[34] Bresnen M, Wray K, Bryman A, Beardsworth A, Ford J, Keil E. The flexibility of recruitment in the construction industry: formalisation or recasualisation?

Sociology, 1985; 19(1).

[35] Jaselskis E, Ashley D. Optimal allocation of project management resource for achieving success. Journal of Construction Engineering and Management, 1991; 117(2): 321-340.

[36] Trejo D, Patil S, Anderson S, Cervantes E. Framework for competency and capability assessment for resource allocation. Journal of Management in Engineering, 2002; January: 44-49. 
[37] Love P, Holt G, Li H. Triangulation in construction management research.

Engineering, Construction and Architectural Management, 2002; 9(4): 294-303.

[38] Yin R. Case study research: design and methods, $2^{\text {nd }}$ ed. London: Sage, 1994.

[39] Attride-Stirling J. Thematic network analysis. Qualitative Research, 2001; 1(3): 385-405.

[40] CIPD. Labour turnover survey report, London: CIPD, 2001. 
Table 1. Employee resourcing activities

\begin{tabular}{|c|c|c|}
\hline HRM objective & HRM activity & Tasks involved \\
\hline \multirow[t]{4}{*}{ Staffing } & $\begin{array}{l}\text { Human resource } \\
\text { planning (HRP) }\end{array}$ & $\begin{array}{l}\text { Strategic human resource forecast (SHRF) - an input; } \\
\text { development of a human resource plan - an output }\end{array}$ \\
\hline & $\begin{array}{l}\text { Recruitment and } \\
\text { selection }\end{array}$ & $\begin{array}{l}\text { Identification and analysis of recruitment needs; drawing } \\
\text { of job descriptions and person specifications; } \\
\text { advertisement of the vacancy; shortlisting candidates; } \\
\text { selection process utilising appropriate selection techniques } \\
\text { (i.e. interviewing, assessment centres, etc.); selection of } \\
\text { the 'right' candidate; induction }\end{array}$ \\
\hline & Team deployment & $\begin{array}{l}\text { Formation and building of effective teams; deconstruction } \\
\text { and redeployment of teams }\end{array}$ \\
\hline & Exit & Redundancy, retirement, dismissal, voluntary exit \\
\hline \multirow[t]{2}{*}{ Performance } & $\begin{array}{l}\text { Performance } \\
\text { management }\end{array}$ & $\begin{array}{l}\text { Continuous evaluation and performance appraisal; } \\
\text { feedback and reward }\end{array}$ \\
\hline & Career management & $\begin{array}{l}\text { Promotion; personal and professional development } \\
\text { planning (PDP) }\end{array}$ \\
\hline HR admin. & $\begin{array}{l}\text { Collection, storage and } \\
\text { use of employee data }\end{array}$ & $\begin{array}{l}\text { Utilisation of appropriate HR administration system, e.g. } \\
\text { manual filing system or a computerised human resource } \\
\text { information system (HRIS) }\end{array}$ \\
\hline
\end{tabular}

